Electrochemistry Communications

Elsevier Editorial system(tm) for

Manuscript Draft

Manuscript Number: EC17-268R1

Title: Copper underpotential deposition at gold surfaces in contact with a deep eutectic solvent. New insights.

Article Type: Short communication

Keywords: Single crystal; deep eutectic solvent; interface; underpotential deposition; chloride

Corresponding Author: Professor Juan M. Feliu,

Corresponding Author's Institution: Universidad de Alicante

First Author: Paula Sebastián

Order of Authors: Paula Sebastián; Elvira Gómez; Víctor Climent; Juan M. Feliu

Abstract: Copper electrodeposition on polycrystalline gold electrode and on $\mathrm{Au}(\mathrm{hkl})$ single crystals was investigated in a deep eutectic solvent (DES). The employed DES consisted on a mix of choline chloride and urea $(1: 2)$. The interface Au(hkl) /DES was studied by using cycling voltammetry in the capacitive region. The blank voltammograms showed characteristic features, not previously reported, that demonstrates the surface sensitivity of this solvent. Afterwards, copper electrodeposition was analyzed, finding that it takes place through the formation of a UPD adlayer, evidencing the surface sensitivity of the phenomena.

Voltammetric profiles showed similarities with those obtained in aqueous solutions containing chloride, suggesting that the copper UPD in this DES is strongly influenced by the presence of chloride 
Dear Richard,

Please find enclosed the revised version of the paper entitled "Copper underpotential deposition at gold surfaces in contact with a deep eutectic solvent. New insights", by Paula Sebastián, Elvira Gómez, Víctor Climent and Juan M. Feliu. We apologize for the delay in sending the revised version since new experiments were performed in order to confirm some of the reviewers' comments, in particular the change of the reference electrode scale. All changes in the revised version are highlighted with a yellow background.

Yours sincerely,

Juan. M. Feliu

Instituto universitario de electroquímica, Universidad de Alicante

juan.feliu@ua.es 
Reviewer(s)' Comments to the Authors, responses, and overview of changes made

Rewiever 1:

In principle this is an interesting paper that may be accepted for publication. However, the authors missed major publications that discuss UPD of $\mathrm{Cu}$ in the presence of chloride ion quantitatively. In a series of papers Shi et al (see: J.Phys.Chem 101(1997)10310; J.Electroanal. Chem. 384(1995)171; Electrochimica Acta 40(1995)9) demonstrated that in the presence of chloride ion CU UPD forms a bilayer in which copper adatoms are sandwiched between the gold surface and the top monolayer of chlorides. The coverages of $\mathrm{Cu}$ and $\mathrm{Cl}$ were measured and reported in these references. XAS provided detailed structural information for this bilayer. This is important information for the discussion of the results in the present paper.

We thank the reviewer for bringing these references to our attention. The new references were added to the discussion of the results.

Moreover, chlorides induce the transformation of the $(\sqrt{3} \times \sqrt{3})$ R30 to a $(5 \times 5)$ in the first UPD peak, while chlorides lay on top of the copper adlayer forming a bilayer structure lattice [38, $40,41]$... So, from these data it is difficult to know whether the charge involved in the UPD region corresponds only to the $\mathrm{Cu}(\mathrm{l})$-Cu reduction or there is also a contribution from the adsorption of the species of the DES on the copper adlayer, likely chloride $[41,48]$.

\section{Reviewer 2:}

This is a nice, apparently careful work which deserves to be published. Unfortunately, the authors do not calculate certain numbers which would give a better foundation of the interpretation; in particular, I miss the Coulombs and the Farads. Instead, the readers get long text on the findings which are clearly seen on the figures. Two examples:

Following reviewer suggestion, we revised the manuscript to add some quantitative measurements from the voltammetric results. With regards to the particular examples given by the reviewer:

a.The diffusion-controlled cathodic peak and the big anodic stripping peak peak is evidently due to bulk Cu deposition and dissolution; to this, the authors present three lines on how the curves look like (it is clear if we look at the figure) - instead, it would be just sufficient to write that the anodic peak charge is $2 \mathrm{mC} / \mathrm{cm}^{2}$ (calculate the exact value) which is about 10 monolayer.

We thank the reviewer for the suggestion, but we have decided not to add charge values for the bulk copper deposition region, (the charge for the anodic region in the particular experiment of figure 2 is $2.1-2.9 \mathrm{mC} \mathrm{cm}^{-2}$ ), since these values are very dependent on the potential limits and therefore, the particular numbers do not add relevant information to the discussion. Instead of that, we have calculated the corresponding charge for the voltammetric region considered as the UPD region and also the charge involved under the feature labelled as (a) in figure $2 \mathrm{~B}$, values that we believe are more interesting for the reader. 
The total charge integrated in the potential region between -0.50 and $-0.16 \mathrm{~V}$ is ca. $146 \mu \mathrm{C} \mathrm{cm}$ (without subtracting the double layer contribution)... In the positive scan, a broad oxidation peak (peak a') shifted with respect to the oxidation of bulk copper ( $\left.b^{\prime}\right)$ is observed. The charge integrated in the cathodic scan for peak (a) (between -0.50 and $-060 \mathrm{~V}$, without double layer correction) amounts to ca. $140 \mu \mathrm{C} \mathrm{cm}$.

b. The last four rows of the same paragraph: "The current density in the UPD region increases linearly etc." Where is a plot of showing the linearity (say a $j$ vs $v$ plot)? I would suggest to calculate the $j / v$ (or $j / a b s(v)$ ) for two maybe three curves and plot them together. If they coincide, then one can claim that it is linear. If the authors would have calculated the Farads $(j / v)$ and the integral of the Farads over potential (or the integral of current over time), they would have got an approximately one monolayer charge - and then could have concluded that this is one monolayer of Cu UPD or adsorption/desorption of one monolayer of chloride. The authors should do the calculations rather than the verbalization.

Values of the charges for the corresponding UPD region were added. Figure 2 was modified and a new plot of the ( $j v s v$ ) and ( $C v s v$ ) was added demonstrating that the processes involved in the potential region between -0.50 and $0.10 \mathrm{~V}$ vs $\mathrm{Ag} \mid \mathrm{AgCl}$ (both UPD and capacitive) are adsorption controlled (Figure 2D).

\section{Miscellaneous minor items:}

a. In the context of Fig.2a: "the typical nucleation loop" - explain or omit. Or at least, write that "counter-clockwise loop which is typical..."

This a widely used expression in metal deposition kinetics. Still, a new reference was added to the revised version that we hope it helps to clarify the question.

b. Figure scaling: please use "integer numbers" - the draw ticks at every $0.1,0.2$ or $0.5 \mathrm{~V}$, rather than at every 0.3 or $0.7 \mathrm{~V}$. The insets of Fig. $2 a$ and $2 b$ will be invisibly small in the printed version. Draw a thin line at $j=0$.

Figure scaling was corrected and insets were removed in the new version. $A$ thin line was drawn at $\mathrm{j}=0$ in figure $2 \mathrm{~A}$ and figure $2 \mathrm{~B}$.

c. In the context of Fig.3A: "The second pair of peaks was assigned to a full monolayer". Of what, and why?

This paragraph was modified in the new version as follows:

The charge involved within these characteristic UPD peaks (i.e. subtracting a constant pseudocapacitance value as measured at $-0.5 \mathrm{~V}, 180 \mu \mathrm{F} \mathrm{cm}$ ) is around $240 \mu \mathrm{C} \mathrm{cm}$, a value that would approach quite well to the corresponding value for a whole copper monolayer ( $220 \mu \mathrm{C}$ $\mathrm{cm}^{-2}$ ), assuming that here the copper deposition only involves the transference of one electron 
$(\mathrm{Cu}(\mathrm{l})-\mathrm{Cu})$, and neglecting any coulometric contribution from anion adsorption [45].

d. Fig.3B: "the corresponding counter peak is broader and splits in two peaks" - I see one peak and a very tiny broadening of the line.

This paragraph was modified in the new version as follows:

However, whereas in the positive scan a sharp peak is observed, in the negative scan the corresponding counter peak splits in a very thin peak overlapped with a broader one.

The following lines, referred to copper UPD on $\mathrm{Au}(100)$, were also added to the same paragraph.

The corresponding charge for the UPD feature, integrated after subtracting the pseudocapacitance measured at $-0.50 \mathrm{~V}\left(70 \mu \mathrm{F} \mathrm{cm}^{-2}\right)$, is around $130 \mu \mathrm{C} \mathrm{cm}^{-2}$ (while the total charge for a whole copper monolayer deposited on $\mathrm{Au}(100)$ is ca. $190 \mu \mathrm{C} \mathrm{cm}^{-2}$ [45]).

Reviewer 3:

This is a manuscript from one of the pioneering groups in the field of single crystal electrochemistry. The manuscript reported a study on the electrochemical behaviors of gold single crystal electrodes and Cu UPD on gold single crystal electrodes in a deep eutectic solvent. The topic is very important from the point of view of the fundamental electrochemistry. Therefore, I recommend urgent publication of the manuscript subject to following minor revisions:

1. The current peaks in Figure $2 B$ are described as Peaks $a, b, a^{\prime}$ and $b^{\prime}$ in the text, in the Figure the peaks should be marked correspondingly for better understanding.

Figure 2B was corrected by adding the corresponding labels.

2. A Cu wire was used as reference electrode, but the potential of the Cu wire in deep eutectic solvent without $\mathrm{Cu}(\mathrm{I})$ should be different from that with $\mathrm{Cu}(\mathrm{I})$. It is better to measure the potential of the CU wire versuS SCE and include the values in the experimental section, which benefits the comparison with cyclic voltammetric data in literature.

We agree with the referee. In the revised version, all potentials are referred to $\mathrm{Ag} \mid \mathrm{AgCl}$ reference electrode.

In addition of the modification listed above in response to the reviewers, the language of the whole manuscript was carefully checked and a few expressions were corrected. 
In this paper we have investigated the interface $\mathrm{Au}($ poly) and $\mathrm{Au}(\mathrm{hkl})$ in contact with deep eutectic solvent (DES). We also have investigated copper electrodeposition and copper UPD formation on these surfaces. We have found very characteristic blank cyclic volatmmograms with sharp spikes not reported before for a DES. These sharp peaks are strongly structure sensitive. Moreover we have also observed copper UPD formation on gold surfaces in this DES. The copper UPD voltammograms are also strongly sensitive to the crystallogrfic orientation and show sharp spikes and similarities with those reported in aqueous solutions due to the high chloride concentration in the DES. These results have not been reported before and deserve urgent publication. 
Bingwei Mao

Xiamen University

bwmao@xmu.edu.cn

Jacek Lipkowski

Guelph University

jlipkows@uoguelph.ca

Tamás Pajkossy

Hungarian Academy of Sciences

pajkossy@chemres.hu

M.C. Costa Figueiredo

Leiden University

m.c.costa.figueiredo@lic.leidenuniv.nl 
- The interfaces $\mathrm{Au}($ poly) and $\mathrm{Au}(\mathrm{hkl})$ in contact with a DES are investigated.

- Cyclic voltammograms showed singular features and sharp peaks.

- Copper electrodeposition on gold surface is preceded by the formation of a UPD monolayer.

- Copper UPD on Au(hkl) is structure sensitive.

- Copper UPD on $\mathrm{Au}($ poly) and $\mathrm{Au}(\mathrm{hkl})$ is influenced by the presence of chloride from the DES. 


\title{
Copper underpotential deposition at gold surfaces in contact with a deep eutectic solvent. New insights
}

\author{
Paula Sebastián ${ }^{1}$, Elvira Gómez ${ }^{2}$, Víctor Climent ${ }^{1}$ and Juan M. Feliu ${ }^{1 *}$
}

1. Instituto de Electroquímica. Universidad de Alicante. Apdo. 99. 03080 Alicante. España.

2. Grup d'Electrodeposició de Capes Primes i Nanoestructures (GE-CPN). Dep. Ciència de Materials i Química Física and Institut de Nanociència i Nanotecnologia (IN2UB). Universitat de Barcelona 08028 Barcelona. España

Corresponding author*

E-mail addres: juan.feliu@ua.es (J.M. Feliu)

\section{KEY WORDS}

Single crystal, deep eutectic solvent, interface, underpotential deposition, chloride.

\section{HIGHLIGHTS}

The interfaces $\mathrm{Au}($ poly) and $\mathrm{Au}(\mathrm{hkl})$ in contact with a DES are investigated.

Cyclic voltammograms showed singular features and sharp peaks.

Copper electrodeposition on gold surface is preceded by the formation of a UPD monolayer.

Copper UPD on $\mathrm{Au}(\mathrm{hkl})$ is structure sensitive.

Copper UPD on $\mathrm{Au}($ poly) and $\mathrm{Au}(\mathrm{hkl})$ is influenced by the presence of chloride from the DES.

\section{ABSTRACT}

Copper electrodeposition on polycrystalline gold electrode and on Au(hkl) single crystals was investigated in a deep eutectic solvent (DES). The employed DES consisted on a mix of choline chloride and urea (1:2). The interface Au(hkl) /DES was studied by using cycling voltammetry in the capacitive region. The blank voltammograms showed characteristic features, not previously reported, that demonstrates the surface sensitivity of this solvent. Afterwards, copper electrodeposition was analyzed, finding that it takes place through the formation of a UPD adlayer, evidencing the surface sensitivity of the phenomena. Voltammetric profiles showed similarities with those obtained in aqueous solutions containing chloride, suggesting that the copper UPD in this DES is strongly influenced by the presence of chloride. 


\section{INTRODUCTION}

From the incorporation of ionic liquids as effective solvents, their use in electrochemical processes has been widespread $[1,2]$. The initial instability of the prepared liquids gave way to the search of air and water stable liquids. Among them, deep eutectic solvents were introduced as a green and cheap alternative. These room temperature liquids are prepared by mixing a hydrogen-bond donor with a quaternary ammonium salt [1, 3-9].

DESs have been widely employed in electrodeposition processes given their high solubilizing capacity of metal ions. Different aspects of the prepared coatings have been studied: morphology, stress, corrosion, even first stages of deposition process [10-18]. However, the number of studies devoted to the interaction of solvent molecules with the electrode surface and its possible effect on the electrodeposition process is very scarce $[19,20]$. In this work, copper deposition on gold from a DES composed of a urea:choline chloride (2:1 molar ratio) has been studied, focusing the attention on the interaction between the solution components and the substrate. For that, gold single crystal electrodes were employed and the interface $\mathrm{Au}(\mathrm{hkl}) \mid \mathrm{DES}$ was initially investigated.

\section{EXPERIMENTAL}

Working electrodes were prepared from single crystal beads, as reported elsewhere [21]. The polycrystalline sample was a polyoriented single crystal bead, Au(poly). As a reference electrode, a Cu wire was used while a gold wire was used as counter electrode. The potentials were further referred to the $\mathrm{Ag}|\mathrm{AgCl}| 3 \mathrm{M} \mathrm{KCl}$ reference electrode. All working electrodes were flame annealed and cooled down in Ar atmosphere to ambient temperature before immersion in the cell. Electrochemical experiments were performed in a small volume cell and controlled by a $\mu$-Autolab (Eco-Chemie, Ultrecht, The Netherlands). The temperature of all the experiments was kept at $40 \circ \mathrm{C}$ using a thermostated bath.

Urea (Merck p.a.) and choline chloride (Across, 99\%) were mixed (molar rate 2:1) at low temperature $(T<40 \circ \mathrm{C})$. Before the experiment, the DES was kept under vacuum $(\mathrm{P}<0.002 \mathrm{mbar})$ and $30 \circ \mathrm{C}$ overnight under stirring [22]. $\mathrm{CuCl}$ and $\mathrm{CuCl}_{2}$ (p.a. quality) were also purchased from Merck. 


\section{RESULTS AND DISCUSION}

A detailed voltammetric study of the capacitive potential region between -0.95 and $0.40 \mathrm{~V}$ vs $\mathrm{Ag} \mid \mathrm{AgCl}$ was performed on $\mathrm{Au}($ poly), revealing singularities of the $\mathrm{Au}($ poly) | DES interface (Figure 1A). The voltammogram shows a capacitive current (capacity around $50 \mu \mathrm{F} \mathrm{cm}^{-2}$ ) that increases linearly with the scan rate. Overlapped with this capacitive current, a few broad peaks ( $w$, $a$ and $b$ ) and one small quite sharp peak (c) appear in the positive scan. The counter peaks also appear in the reverse scan evidencing quasi-reversible behavior. The lack of perfect reversibility can be ascribed to the high viscosity, and low mobility of ions in solution. The appearance of these peaks is most likely related to $2 \mathrm{D}$ phase transitions involving the species of the electrolyte. In particular, the sharp peaks have been ascribed to several phase transitions in the anion adlayer, and were previously reported in aqueous solution [23-25] and recently in the [Emmim] $\left[T f_{2} \mathrm{~N}\right]$ RTIL [26]. It is worth mentioning that chloride concentration in the solvent is around 4.8M [27, 28], so a strong effect of the chloride adsorption is expected. The low current intensity of these peaks is due to the small size of the corresponding facets of the Au bead. Thus, single crystal electrodes were also employed to explore this capacitive region in more detail. Figures $1 \mathrm{~B}$ and $\mathrm{1C}$ show the cyclic voltammograms in the capacitive zone of $A u(111)$ and $A u(100)$ in contact with the DES. As expected, the response is sensitive to the surface structure. For the $\mathrm{Au}(111)$ orientation, the group of peaks labelled as $a, b$ and $c$ (Figure 1B) in the positive scan, appears approximately at the same potential position as the corresponding peaks for the polycrystalline bead (Figure 1A). A new small peak at higher potentials (d, Figure 1B) not observed on the $A u($ poly), is also observed on $A u(111)$. These results evidence that the voltammetric profile of $A u(p o l y)$ has major contribution from (111) orientation, because these facets are the largest (disordered regions do not contribute sharp peaks). After reversing the scan, a similar group of peaks were found in the negative scan, but the lack of symmetry between positive and negative scans is now more evident, supporting that the structuration of the solvent takes place slowly. Other possible contributions to the voltammogram are related with the existence of surface reconstruction, which are strongly linked to the anion adsorption, as was previously observed on Au surfaces in aqueous electrolytes [23]. Cyclic voltammetry for $\mathrm{Au}(100)$ was also recorded (Figure 1C), whose profile differs clearly from the previous one. In the high potential region, a group of quasi reversible peaks is observed $\left(x, y, z\right.$ and the counter peaks $x^{\prime}, y^{\prime}$ and $\left.z^{\prime}\right)$ while around $-0.25 \mathrm{~V} v \mathrm{Ag} \mid \mathrm{AgCl}$ the more prominent peak $(w)$ appears in the positive scan. The latter is also observed for the $\mathrm{Au}($ poly), but in much lower extent, most likely reflecting that contribution from (100) facets is very small in the polyoriented bead. This peak is also similar to that ascribed to the lifting of 
the hexagonal reconstruction characteristic of $(100)$ surfaces $[23,29]$. The counter peak was not clearly identified and two broad peaks were found instead $\left(v^{\prime}\right.$ and $\left.w^{\prime}\right)$, suggesting that the surface reconstruction is slow and irreversible.

It is important to highlight that all the cyclic voltammetries recorded between -0.95 and $0.40 \mathrm{~V}$ vs $\mathrm{Ag} \mid \mathrm{AgCl}$ were stable in consecutive scans, also in $\mathrm{Au}(111)$, contrary to that described in [Emmim] $\left[\mathrm{Tf}_{2} \mathrm{~N}\right][26]$. It is evident that the complexity of the voltammetric response reflects the particular nature of the solvent. How the solvent network structures in the interface $A u(h k l) \mid$ DES should likely involve the chloride, but also both the urea and the choline contribute [30, 31].

Finally, the potential window voltammograms from the blank solution on $\mathrm{Au}(\mathrm{hkl})$ and $\mathrm{Au}($ poly) were recorded (Figure 1D), showing in the negative scan a pair of surface insensitive broad peaks. Similar peaks were observed in other metal surfaces and assigned to a previous step of the massive reduction of the solvent. In the positive scan, no relevant oxidation features were recorded before the massive oxidation of the solvent. After attaining the oxidation limit, a reduction peak appears in the reverse scan, which increases by increasing the upper potential limit. In any case, the electrochemical window is not higher than $2.3 \mathrm{~V}$, being shorter than that of convectional RTILs (3-5 V) [2].

After the characterization of the blank response from the solvent, copper electrodeposition was investigated, first on poly( $\mathrm{Au})$ electrode. Figure 2 shows the copper electrodeposition on the gold bead, in $10 \mathrm{mM} \mathrm{CuCl}$ solution. The $\mathrm{Cu}(\mathrm{l})$ state is stabilized by chloride complexation. A quasi-reversible $\mathrm{Cu}(\mathrm{II})-\mathrm{Cu}(\mathrm{I})$ redox process appears around $0.29 \mathrm{~V}$, well separated from the $\mathrm{Cu}(\mathrm{I})-\mathrm{Cu}$ electrodeposition [17, 28, 32]. The cyclic voltammogram for the $\mathrm{Cu}(\mathrm{I})$ electrodeposition shows a fast increase of the cathodic current with a diffusion controlled maximum. By reversing the scan, a sharp oxidation peak appears, evidencing the easy dissolution of the copper deposit likely because the high chloride concentration in the DES favors it. Interestingly, reversing the scan at the beginning of main reduction current the typical nucleation loop does not show [33], suggesting that the initial steps of the copper electrodeposition could involve the formation of one copper submonolayer before reaching nucleation and growth regime $[34,35]$. Figure $2 B$ shows the cyclic voltammetry recorded just before the bulk deposition of copper. Around -0.37 and $0.06 \mathrm{~V}$ two pairs of peaks (dashed line) appear which could be related with copper UPD, mainly in the ordered domains. The total charge integrated in the potential region between -0.50 and $0.16 \mathrm{~V}$ is ca. $146 \mu \mathrm{C} \mathrm{cm}^{-2}$ (without subtracting the double layer contribution). By increasing slightly the negative limit (-0.6 V vs 
$\mathrm{Ag} \mid \mathrm{AgCl}$ ), a small peak (a) overlaps with the bulk deposition. In the positive scan, a broad oxidation peak (peak a') shifted with respect to the oxidation of bulk copper ( $\left.b^{\prime}\right)$ is observed. The charge integrated in the cathodic scan for peak (a) (between -0.50 and $-060 \mathrm{~V}$, without double layer correction) amounts to ca. $140 \mu \mathrm{C} \mathrm{cm}^{-2}$. A preliminary explanation of these results is that a second or even few monolayers could grow layer by layer over the first UPD layer before reaching the growth regime, as previously reported [36]. Moreover, the current density within the potential region between -0.50 and $0.16 \mathrm{~V}$, hereby considered as the UPD region, increases linearly with the scan rate (Figure 2C and 2D). This result evidences that the whole process takes place on the surface (both the UPD and the minor capacitive contribution). So, our results support that UPD is the previous step before the copper bulk deposition in the DES, since copper UPD was previously reported on gold electrodes in aqueous electrolytes [37] and also in this DES on platinum electrodes [32].

In order to get insight on the copper UPD step, single crystals were employed. Figure $3 \mathrm{~A}$ and 3B show the $\mathrm{Cu}$ UPD potential range on $\mathrm{Au}(111)$ and $\mathrm{Au}(100)$, respectively. The whole $\mathrm{Cu}$ UPD on $\mathrm{Au}(111)$ involves two groups of peaks. The first pair of peaks is located at the most positive potentials ( $0.10 \mathrm{~V}$ vs $\mathrm{Ag} \mid \mathrm{AgCl}$ ), while the other pair is located near the onset of the copper deposition (centered around $-0.42 \mathrm{~V}$ vs $\mathrm{Ag} \mid \mathrm{AgCl}$ ). Similar group of signals were reported in aqueous solutions containing chloride, medium in which it was made evident that the specific nature of the anions affects the UPD process $[37,38]$. In sulphate containing solutions the more positive pair of peaks was assigned to the formation of a $(\sqrt{3} \times \sqrt{ } 3)$ R30을 honeycomb [39]. The second pair of peaks was assigned to a full copper monolayer. The presence of chloride shifts the position of the peaks and also its reversibility. Moreover, chlorides induce the transformation of the $(\sqrt{3} \times \sqrt{3})$ R30 to a $(5 \times 5)$ in the first UPD peak, while chlorides lay on top of the copper adlayer forming a bilayer structure lattice $[38,40,41]$. Because chloride interacts strongly with copper, it is expected that the high chloride concentration in the DES plays an important role in the final structure of the UPD adlayers. However, the voltammetric profile that we report here show a few differences from those previously reported in aqueous solutions, since the two groups of peaks appear more separated in the potential range and show less reversibility. These differences can be attributed to the presence of the other species of the DES (the choline and the urea), since the addition of organic compounds can modify the UPD region [42-44]. The charge involved within these characteristic UPD peaks (i.e. subtracting a constant pseudo-capacitance value as measured at $-0.5 \mathrm{~V}, 180 \mu \mathrm{F} \mathrm{cm}$ ) is around $240 \mu \mathrm{C} \mathrm{cm}^{-2}$, a value that would approach quite well to the corresponding value for a whole copper monolayer ( $220 \mu \mathrm{C} \mathrm{cm}^{-2}$ ), assuming that here the copper deposition only 
involves the transference of one electron $(\mathrm{Cu}(\mathrm{I})-\mathrm{Cu})$, and neglecting any coulometric contribution from anion adsorption [45].

The cyclic voltammetry for the copper UPD on $A u(100)$ shows only a pair of quasi reversible peaks around $0.142 \mathrm{~V}$ vs $\mathrm{Ag} \mid \mathrm{AgCl}$. The corresponding charge for the UPD feature, integrated after subtracting the pseudo-capacitance measured at $\left.-0.50 \mathrm{~V}(70 \mu \mathrm{F} \mathrm{cm})^{-2}\right)$, is around $130 \mu \mathrm{C}$ $\mathrm{cm}^{-2}$ (while the total charge for a whole copper monolayer deposited on $\mathrm{Au}(100)$ is ca. $190 \mu \mathrm{C}$ $\left.\mathrm{cm}^{-2}[45]\right)$.

The profile reported here is very similar to that recorded in chloride containing aqueous solutions. However, whereas in the positive scan a sharp peak is observed, in the negative scan the corresponding counter peak splits in a very thin peak overlapped with a broader one. This result evidences that the particular nature of the DES affects the UPD process although a strong interaction between the copper adlayer and the chloride is also expected [36, 46, 47].

It is worth pointing out that the onset of the UPD process takes place immediately after the first $\mathrm{Cu}(\mathrm{II}) / \mathrm{Cu}(\mathrm{I})$ electron transfer, even when $\mathrm{CuCl}_{2}(\mathrm{Cu}(\mathrm{II}))$ salt is the copper source (not showed), potentials values at which $\mathrm{Cu}(\mathrm{I})$ is stabilized (Figure $3 \mathrm{C}$ and $3 \mathrm{D}$, dashed lines). This result strongly suggests that the copper UPD on gold electrode in the choline chloride-urea based DES takes place from the stable $\mathrm{Cu}(\mathrm{I})$-chloride complex. So, from these data it is difficult to know whether the charge involved in the UPD region corresponds only to the $\mathrm{Cu}(\mathrm{I})$ - $\mathrm{Cu}$ reduction or there is also a contribution from the adsorption of the species of the DES on the copper adlayer, likely chloride $[41,48]$.

Finally, by enlarging the negative scan (Figure $3 C$ and $3 D$, solid lines), the beginning of the copper bulk deposition is observed. While on $\mathrm{Au}(111)$ only one oxidation peak appears, on $\mathrm{Au}(100)$, two oxidation peaks were detected as well as a broader and less prominent peak that extends to $0.0 \mathrm{~V}$ potential limit. These features could be related with the previous formation of some copper adlayers before reaching the growth regime [36]. More work is needed to understand the phenomena of metal UPD in the DES solvents.

\section{CONCLUSIONS}

Voltammetric experiments were recorded for different Au surfaces in contact with the eutectic mixture of urea and choline chloride DES, revealing that the interfacial behavior is structure 
sensitive. Overlapped with the capacitive current recorded for each electrode, several sharp and characteristic peaks were observed not previously described.

Copper deposition on gold electrodes was also investigated, taking advantage that $\mathrm{Cu}(\mathrm{I})$ solutions can be used. It was found that bulk copper deposition is preceded by the previous formation of a UPD copper adlayer. Copper UPD on $\mathrm{Au}(111)$ and $\mathrm{Au}(100)$ showed characteristic sharp peaks and similar profiles to those recorded in chloride containing aqueous solutions. Thus, chloride is likely involved in the UPD formation. These preliminary results indicate that the UPD in the DES takes place from the stabilized $\mathrm{Cu}(\mathrm{I})-\mathrm{Cl}$ complex.

\section{CONFLICT OF INTEREST}

The authors declare no conflict of interest.

\section{ACKNOWLEDGEMENTS}

Financial support from MINECO through projects CTQ2016-76221-P (AEI/FEDER, UE) and TEC2014-51940-C2-2-R (AEI/FEDER, UE) are greatly acknowledged. P. Sebastian also acknowledges MECD for FPU grant. 

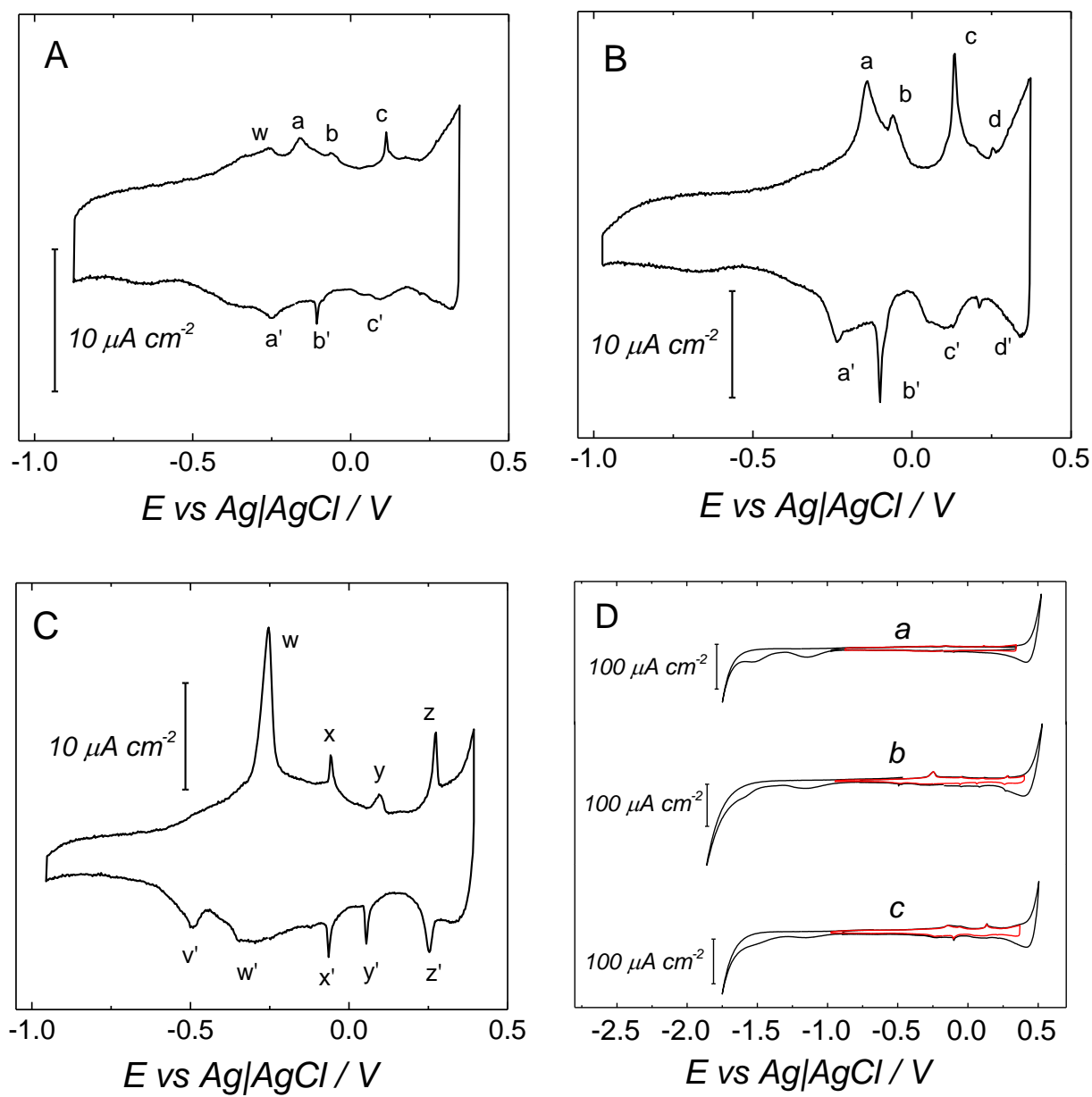

Figure 1. Cyclic voltammograms for A) $A u($ poly), B) $A u(111)$ and C) $A u(100)$ electrodes in contact with the DES, D) large potential window voltammograms for a) $\mathrm{Au}($ poly), b) $\mathrm{Au}(100)$ and c) $\mathrm{Au}(111)$. Scan rate: $50 \mathrm{mV} / \mathrm{s}$ 

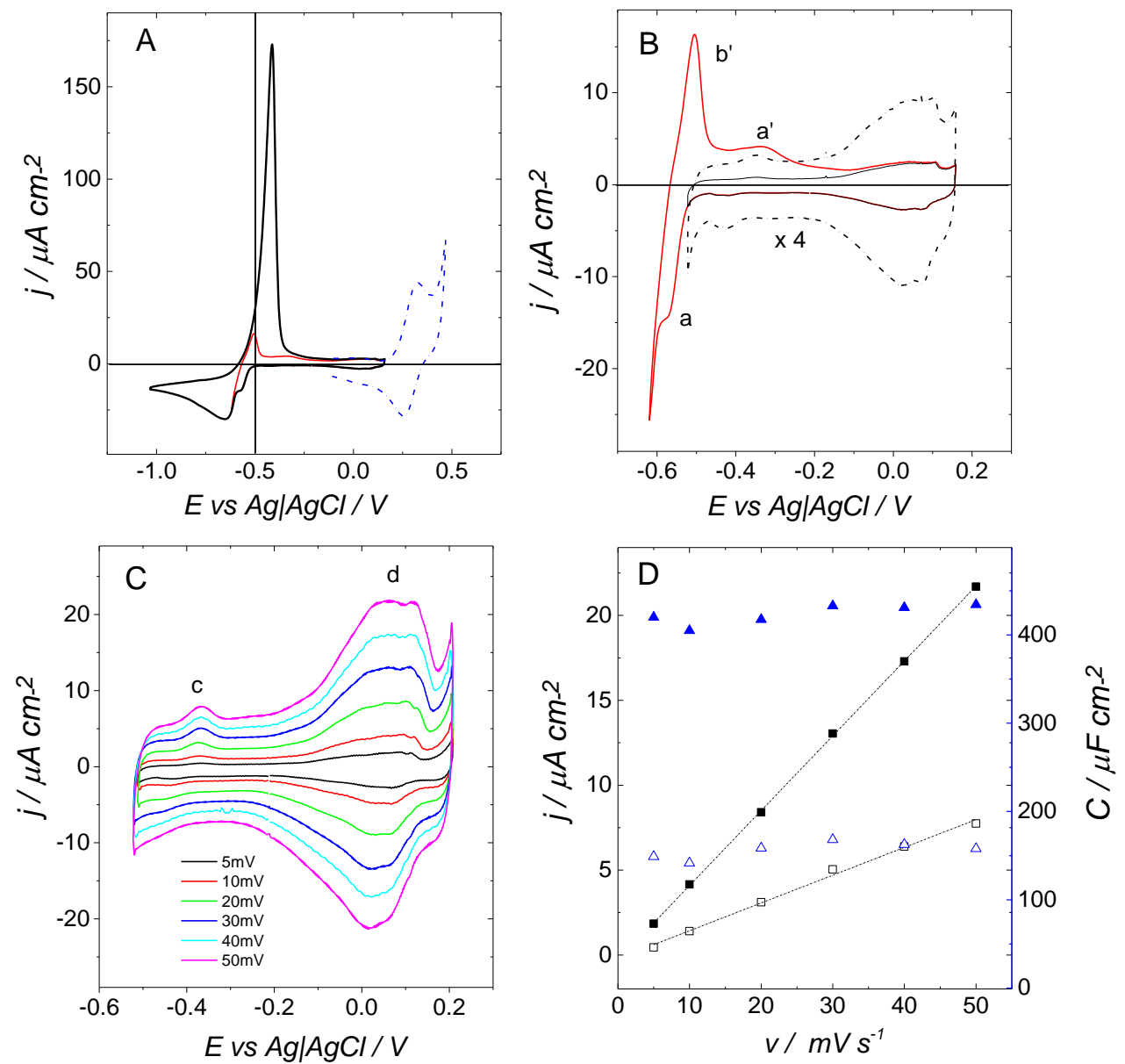

Figure 2. Cyclic voltammograms for copper electrodeposition on $\mathrm{Au}$ (poly) from a $10 \mathrm{mM} \mathrm{CuCl}+$ DES solution: A) and B) different potential limits. (dashed line in B is just an enlargement of the black curve). Scan rate at $5 \mathrm{mV} / \mathrm{s}$. C) Copper UPD recorded at different scan rates. D) plots of current densities (squares) and pseudocapacitance $(j / v)$ (triangles) of the UPD region vs the scan rate. Open and filled symbols corresponds to the maximum values measured at peaks $c$ and $d$ respectively, from figure $2 \mathrm{C}$. Vertical line in figure $2 \mathrm{~A}$ marks the reversible potential for bulk copper deposition. 

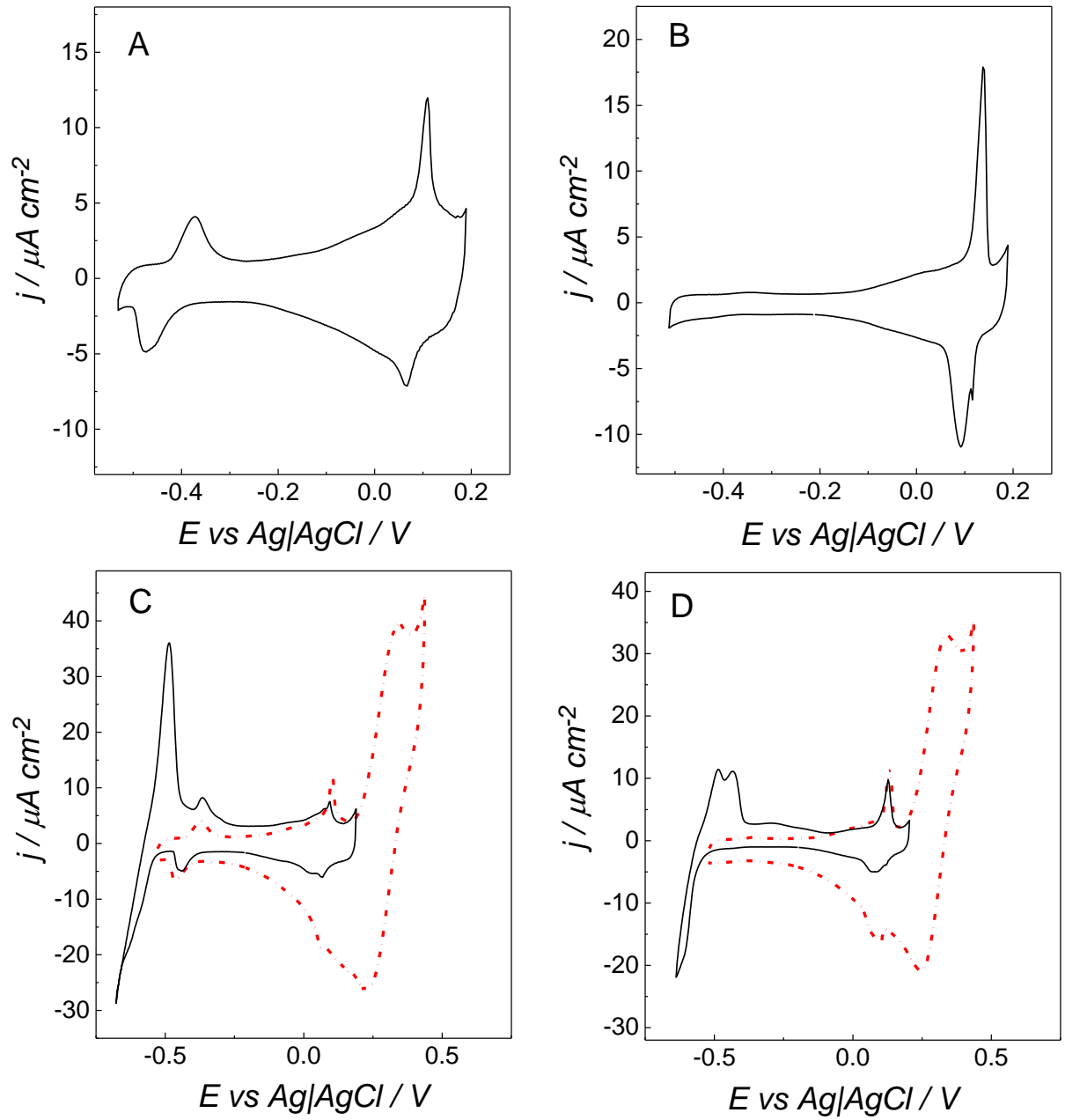

Figure 3. Cyclic voltammograms for $\mathrm{Cu}$ UPD deposition on $\mathrm{Au}(\mathrm{hkl})$ electrodes, from a $10 \mathrm{mM}$ $\mathrm{CuCl}+\mathrm{DES}$ solution. A) $\mathrm{Au}(111)$, B) $\mathrm{Au}(100)$. Potential limits showing the $\mathrm{Cu}(\mathrm{II})-\mathrm{Cu}(\mathrm{I})$ reduction (dashed line) and the onset of bulk deposition (solid line) on : C) $\mathrm{Au}(111)$,D) $\mathrm{Au}(100)$. Scan rate: $5 \mathrm{mV} / \mathrm{s}$. 


\section{REFERENCES}

[1] M. Armand, F. Endres, D.R. MacFarlane, H. Ohno, B. Scrosati, Ionic-liquid materials for the electrochemical challenges of the future, Nature Materials, 8 (2009) 621-629.

[2] M.C. Buzzeo, R.G. Evans, R.G. Compton, Non-haloaluminate room-temperature ionic liquids in electrochemistry - A review, ChemPhysChem, 5 (2004) 1106-1120.

[3] P. Bonhôte, A.-P. Dias, N. Papageorgiou, K. Kalyanasundaram, M. Grätzel, Hydrophobic, Highly Conductive Ambient-Temperature Molten Salts, Inorganic Chemistry, 35 (1996) 11681178.

[4] A.P. Abbott, G. Capper, D.L. Davies, R.K. Rasheed, V. Tambyrajah, Novel solvent properties of choline chloride/urea mixtures, Chemical Communications, (2003) 70-71.

[5] A.P. Abbott, D. Boothby, G. Capper, D.L. Davies, R.K. Rasheed, Deep Eutectic Solvents formed between choline chloride and carboxylic acids: Versatile alternatives to ionic liquids, Journal of the American Chemical Society, 126 (2004) 9142-9147.

[6] A.P. Abbott, R.C. Harris, K.S. Ryder, Application of Hole Theory to Define lonic Liquids by their Transport Properties, The Journal of Physical Chemistry B, 111 (2007) 4910-4913.

[7] E.L. Smith, A.P. Abbott, K.S. Ryder, Deep Eutectic Solvents (DESs) and Their Applications, Chemical Reviews, 114 (2014) 11060-11082.

[8] C.A. Nkuku, R.J. LeSuer, Electrochemistry in Deep Eutectic Solvents, The Journal of Physical Chemistry B, 111 (2007) 13271-13277.

[9] F. Endres, S. Zein El Abedin, Air and water stable ionic liquids in physical chemistry, Physical Chemistry Chemical Physics, 8 (2006) 2101-2116.

[10] Q. Zhang, Q. Wang, S. Zhang, X. Lu, X. Zhang, Electrodeposition in lonic Liquids, ChemPhysChem, 17 (2016) 335-351.

[11] A.R. Hillman, K.S. Ryder, C.J. Zaleski, V. Ferreira, C.A. Beasley, E. Vieil, Application of the combined electrochemical quartz crystal microbalance and probe beam deflection technique in deep eutectic solvents, Electrochimica Acta, 135 (2014) 42-51.

[12] M. Li, Z. Wang, R.G. Reddy, Cobalt electrodeposition using urea and choline chloride, Electrochimica Acta, 123 (2014) 325-331.

[13] A.P. Abbott, K.El Ttaib, G. Frisch, K.S. Ryder, D. Weston, The electrodeposition of silver composites using deep eutectic solvents, Physical Chemistry Chemical Physics, 14 (2012) 24432449.

[14] A.P. Abbott, A. Ballantyne, R.C. Harris, J.A. Juma, K.S. Ryder, Bright metal coatings from sustainable electrolytes: the effect of molecular additives on electrodeposition of nickel from a deep eutectic solvent, Physical Chemistry Chemical Physics, 19 (2017) 3219-3231.

[15] H. Yang, X. Guo, N. Birbilis, G. Wu, W. Ding, Tailoring nickel coatings via electrodeposition from a eutectic-based ionic liquid doped with nicotinic acid, Applied Surface Science, 257 (2011) 9094-9102.

[16] A. Florea, L. Anicai, S. Costovici, F. Golgovici, T. Visan, Ni and Ni alloy coatings electrodeposited from choline chloride-based ionic liquids - Electrochemical synthesis and characterization, Surface and Interface Analysis, 42 (2010) 1271-1275.

[17] P. Sebastián, E. Torralba, E. Vallés, A. Molina, E. Gómez, Advances in Copper Electrodeposition in Chloride Excess. A Theoretical and Experimental Approach, Electrochimica Acta, 164 (2015) 187-195. 
[18] P. Sebastian, E. Valles, E. Gomez, Copper electrodeposition in a deep eutectic solvent. First stages analysis considering $\mathrm{Cu}(\mathrm{I})$ stabilization in chloride media, Electrochimica Acta, 123 (2014) 285-295.

[19] R. Costa, M. Figueiredo, C.M. Pereira, F. Silva, Electrochemical double layer at the interfaces of Hg/choline chloride based solvents, Electrochimica Acta, 55 (2010) 8916-8920.

[20] M. Figueiredo, C. Gomes, R. Costa, A. Martins, C.M. Pereira, F. Silva, Differential capacity of a deep eutectic solvent based on choline chloride and glycerol on solid electrodes, Electrochimica Acta, 54 (2009) 2630-2634.

[21] A. Rodes, E. Herrero, J.M. Feliu, A. Aldaz, Structure sensitivity of irreversibly adsorbed tin on gold single-crystal electrodes in acid media, Journal of the Chemical Society, Faraday Transactions, 92 (1996) 3769-3776.

[22] M. Gnahm, D.M. Kolb, The purification of an ionic liquid, Journal of Electroanalytical Chemistry, 651 (2011) 250-252.

[23] D.M. Kolb, Reconstruction phenomena at metal-electrolyte interfaces, Progress in Surface Science, 51 (1996) 109-173.

[24] J. Lipkowski, Z. Shi, A. Chen, B. Pettinger, C. Bilger, lonic adsorption at the Au(111) electrode, Electrochimica Acta, 43 (1998) 2875-2888.

[25] J. Clavilier, The role of anion on the electrochemical behaviour of a $\{111\}$ platinum surface; an unusual splitting of the voltammogram in the hydrogen region, Journal of Electroanalytical Chemistry, 107 (1979) 211-216.

[26] P. Sebastián, V. Climent, J.M. Feliu, Characterization of the interfaces between Au(hkl) single crystal basal plane electrodes and [Emmim][Tf2N] ionic liquid, Electrochemistry Communications, 62 (2016) 44-47.

[27] A.P. Abbott, G. Frisch, H. Garrett, J. Hartley, lonic liquids form ideal solutions, Chemical Communications, 47 (2011) 11876-11878.

[28] A.P. Abbott, K. El Ttaib, G. Frisch, K.J. McKenzie, K.S. Ryder, Electrodeposition of copper composites from deep eutectic solvents based on choline chloride, Physical Chemistry Chemical Physics, 11 (2009) 4269-4277.

[29] A. Cuesta, M. Kleinert, D.M. Kolb, The adsorption of sulfate and phosphate on Au(111) and $\mathrm{Au}(100)$ electrodes: An in situ STM study, Physical Chemistry Chemical Physics, 2 (2000) 56845690.

[30] S. Chen, C. Hwuang, H. Tu, C. Wu, S. Yau, L. Fan, Y. Yang, In situ STM study of the adsorption and electropolymerization of o-, $\mathrm{m}$-, and p-ethylaniline molecules on $\mathrm{Au}(111)$ electrode, Physical Chemistry Chemical Physics, 12 (2010) 9276-9284.

[31] T.W. T. Dretschkow, Structural transitions in organic adlayers - a molecular view, in: K. Wandelt (Ed.), Solid Liquid Interface Properties and Processes - A Surface Science SpringerVerlag, 2003.

[32] T. Tsuda, L.E. Boyd, S. Kuwabata, C.L. Hussey, Electrochemistry of copper(I) oxide in the 66.7-33.3 mol \% urea-choline chloride room-temperature eutectic melt, Journal of the Electrochemical Society, 157 (2010) F96-F103.

[33] S. Fletcher, C.S. Halliday, D. Gates, M. Westcott, T. Lwin, G. Nelson, The response of some nucleation/growth processes to triangular scans of potential, Journal of Electroanalytical Chemistry and Interfacial Electrochemistry, 159 (1983) 267-285.

[34] A.I. Danilov, E.B. Molodkina, A.V. Rudnev, Y.M. Polukarov, J.M. Feliu, Kinetics of copper deposition on $\mathrm{Pt}\left(\begin{array}{lll}1 & 1 & 1\end{array}\right)$ and $\mathrm{Au}\left(\begin{array}{lll}1 & 1 & 1\end{array}\right)$ electrodes in solutions of different acidities,

Electrochimica Acta, 50 (2005) 5032-5043.

[35] A.I. Danilov, E.B. Molodkina, Y.M. Polukarov, V. Climent, J.M. Feliu, Active centers for Cu UPD-OPD in acid sulfate solution on Pt(111) electrodes, Electrochimica Acta, 46 (2001) 31373145.

[36] R.J. Randler, D.M. Kolb, B.M. Ocko, I.K. Robinson, Electrochemical copper deposition on $\mathrm{Au}(100)$ : a combined in situ STM and in situ surface X-ray diffraction study, Surface Science, 447 (2000) 187-200. 
[37] E. Herrero, L.J. Buller, H.D. Abruna, Underpotential deposition at single crystal surfaces of $\mathrm{Au}, \mathrm{Pt}, \mathrm{Ag}$ and other materials, Chemical Reviews, 101 (2001) 1897-1930.

[38] Z. Shi, S. Wu, J. Lipkowski, Coadsorption of metal atoms and anions: $\mathrm{Cu}$ upd in the presence of SO42-, Cl- and Br-, Electrochimica Acta, 40 (1995) 9-15.

[39] T. Hachiya, H. Honbo, K. Itaya, Detailed underpotential deposition of copper on gold(III) in aqueous solutions, Journal of Electroanalytical Chemistry and Interfacial Electrochemistry, 315 (1991) 275-291.

[40] H. Matsumoto, I. Oda, J. Inukai, M. Ito, Coadsorption of copper and halogens on Pt(111) and $\mathrm{Au}(111)$ electrode surfaces studied by scanning tunneling microscopy, Journal of Electroanalytical Chemistry, 356 (1993) 275-280.

[41] Z. Shi, S. Wu, J. Lipkowski, Investigations of $\mathrm{Cl}$-adsorption at the $\mathrm{Au}(111)$ electrode in the presence of underpotentially deposited copper atoms, Journal of Electroanalytical Chemistry, 384 (1995) 171-177.

[42] C.M. Whelan, M.R. Smyth, C.J. Barnes, The influence of heterocyclic thiols on the electrodeposition of Cu on Au(111), Journal of Electroanalytical Chemistry, 441 (1998) 109129.

[43] M.H. Hölzle, C.W. Apsel, T. Will, D.M. Kolb, Copper Deposition onto Au(I 11) in the Presence of Thiourea, Journal of the Electrochemical Society, 142 (1995) 3741-3749. [44] F. Endres, A. Schweizer, The electrodeposition of copper on Au(111) and on HOPG from the 66/34 mol\% aluminium chloride/1-butyl-3-methylimidazolium chloride room temperature molten salt: an EC-STM study, Physical Chemistry Chemical Physics, 2 (2000) 5455-5462.

[45] H. Angerstein-Kozlowska, B.E. Conway, A. Hamelin, L. Stoicoviciu, Elementary steps of electrochemical oxidation of single-crystal planes of $\mathrm{Au}-\mathrm{I}$. Chemical basis of processes involving geometry of anions and the electrode surfaces, Electrochimica Acta, 31 (1986) 10511061.

[46] F.A. Möller, O.M. Magnussen, R.J. Behm, In situ STM studies of $\mathrm{Cu}$ underpotential deposition on $\mathrm{Au}(100)$ in the presence of sulfate and chloride anions, Physical Review B, 51 (1995) 2484-2490.

[47] N. Ikemiya, S. Miyaoka, S. Hara, In situ observations of the initial stage of electrodeposition of $\mathrm{Cu}$ on $\mathrm{Au}(100)$ from an aqueous sulfuric acid solution using atomic force microscopy, Surface Science, 327 (1995) 261-273.

[48] S. Wu, Z. Shi, J. Lipkowski, A.P. Hitchcock, T. Tyliszczak, Early Stages of Copper Electrocrystallization: Electrochemical and in Situ X-ray Absorption Fine Structure Studies of Coadsorption of Copper and Chloride at the $\mathrm{Au}(111)$ Electrode Surface, The Journal of Physical Chemistry B, 101 (1997) 10310-10322. 
